\title{
The Tutor Training Method of the New College Teachers
}

\author{
Meng Zhang ${ }^{\mathrm{a}}$, Li Zhang ${ }^{\mathrm{b}}$, Dening Zhang ${ }^{\mathrm{c}}$, Nan Wang ${ }^{\mathrm{d}}$, Zhenjiang Cai ${ }^{\mathrm{e}}$ and \\ Limin Shao $f, *$
}

College of Mechanical and Electrical Engineering, Agricultural University of Hebei, Baoding 071001, China

a603691640@qq.com, b80756373@qq.com, c78750682@qq.com, dcmwn@163.com, eczj65@163.com, fshaolm@126.com

\begin{abstract}
This paper combines the new teachers' needs and the college development together; it analyzes the existing problems in the training courses, colleges work, and even everyday life of young teachers. Then our colleges find a method for new teachers' training, the tutor training methods, an experienced professor as a tutor for a new teacher. It has many advantages. It can improve the basic skills of new teachers' teaching, as teaching organization, teaching evaluation, teaching research, teaching innovation ability. A new teacher can quickly integrate into the scientific research team. Tutors even give guidance on aspects of life. It can enhance the overall level of new teachers’ professional skills.
\end{abstract}

Keywords: New teachers; tutor training method; professional skills.

\section{Introduction}

Young teachers become a more and more important part of college teachers nowadays. With the enrollment increasing number of college students, the number of young teachers increases quickly. The teaching quality requirements also rise, college teacher's contact with the majority of college students directly, and to the development of college teaching and scientific research, some young teachers' teaching skills and academic ability cannot fully meet the requirements of the students and the college ${ }^{[1-4]}$.

Through research and literature, analyzed teaching and scientific research status of young teachers, according to the professional requirements of the college, as professional discipline knowledge, research basic skills; pedagogical teaching knowledge, practical teaching skills, morality level, self-planning capacity and other respects organically together. Applied to the management of tutor training method to young teachers for improving of teaching and scientific research ability.

\section{Professional Requirements of Young College Teachers}

Young college teachers have high education level, broad knowledge, strong professional skills, but they also have an urgent need for professional development and self-development. Competency standards of young college teachers should not only consider scientific and academic ability, but also consider the overall quality of teachers and morality level ${ }^{[5-6]}$. College teachers should have the following professional qualities:

(1) The professional disciplinary knowledge and the basic ability to engage in scientific research work.

(2) The teaching pedagogy knowledge, systems, comprehensive and theoretical teaching knowledge and practical skills.

(3) Young college teachers should have passion for education, have responsibility and dedication for education, and also have good ethics.

(4) Young college teachers should develop their initiative; design their own career development plan.

Thus, young college teachers should both have professional knowledge and pedagogical knowledge, but also a sense of innovation to improve their overall quality. It should be based on the actual needs of the college and the professional requirements of young teachers. To effectively 
promote the professional development of young teachers is a problem we need to solve and the young teacher also should realize that teacher is not just a kind of established occupation but a lifelong pursuit

\section{Existing Problems of Young College Teachers}

Statutory arrangements for induction of Newly Qualified Teacher introduced in 1999 in UK. These new teachers must complete a period of three semesters or the equivalent of three-semester orientation in order to continue work in public or private schools teach. Teacher training is necessary. Currently, the college's vocational training programs and requirements are just external; there are some problems for new young teachers' training methods. Young teacher training in order to be effective, the young teachers also need to under their own circumstances, strengthen weak links, study for the application. Existing problems of young college teachers are the followings:

(1) Non-Normal graduation. Colleges and universities, there are a large number of young teachers graduated from non-normal college. Although a master's degree in general, but they have not professionally trained as in normal university. The systematic grasp of the scientific education theory, awareness of education laws, compliance with the teaching principles, and gain in scientific teaching methods, teaching continued standardization, and better achieved teaching objectives in a relatively short period of time is a serious problem.

(2) Valuing scientific research above teaching work. Most colleges and universities are now valuing scientific research above teaching work institutions, teachers commentary titles, evaluation, the award-winning paper, are related to scientific research and papers, the actual effect of teaching for ranking schools is insignificant. Under such a system, college teachers will naturally energy into research work, and can care about good teaching.

(3) At the initial stage of career, some young teachers are eager to produce results while ignoring the quality. This relatively leisurely and less stressful career has been replaced by increasingly fierce competition and overtime. To face pressure from the aspect of teaching, research, social work and others, causing some teachers appear not correct academic attitude and lack of professionalism.

(4) Life issues, unable threw him into teaching. Young teachers is just in work, wages and title are relatively low, while life requires a lot of expenses, income and expenditure compression forced many teachers have to engage in a variety of part-time activity, these factors seriously take up the research and teaching time of young teachers, affecting their future academic potential.

Currently, there are problems mainly in professional quality, professionalism, social pressure and other aspects of young teachers.

\section{Tutor Training Method of the New College Teachers}

\subsection{Current Teacher Training Method}

Colleges teacher training methods currently limited to pre-training lessons and lectures, pre-training lessons to school is engaged in preliminary vocational training, which is based on the need for teaching positions ${ }^{[1,7-8]}$, to make a preliminary master of education and teaching basic skills for the new teachers, to converse from the role of students or other industry roles to teachers, adapt to the new vocational environment and new professional roles. Pre-training lessons is the initial stage of the vocational education, within the scope of the Vocational Education. Training is concentrated in a few days to complete, it makes the training is very short, and prone to formal tendencies.

Although the lectures of teacher training has many forms, as taking teaching demonstration lectures, typically reports, classroom teaching, practice and commenting. But the reality is generally taken to theory-based classroom education, the traditional "injection" and "chalk and talk" teaching methods, centralized way of teaching leading new teachers cannot be specific, and have no chance of one to one practical guidance. Although there are interactive classroom teaches but still accounted for a major part, it cannot play a real role in guiding significance for the young teachers. 


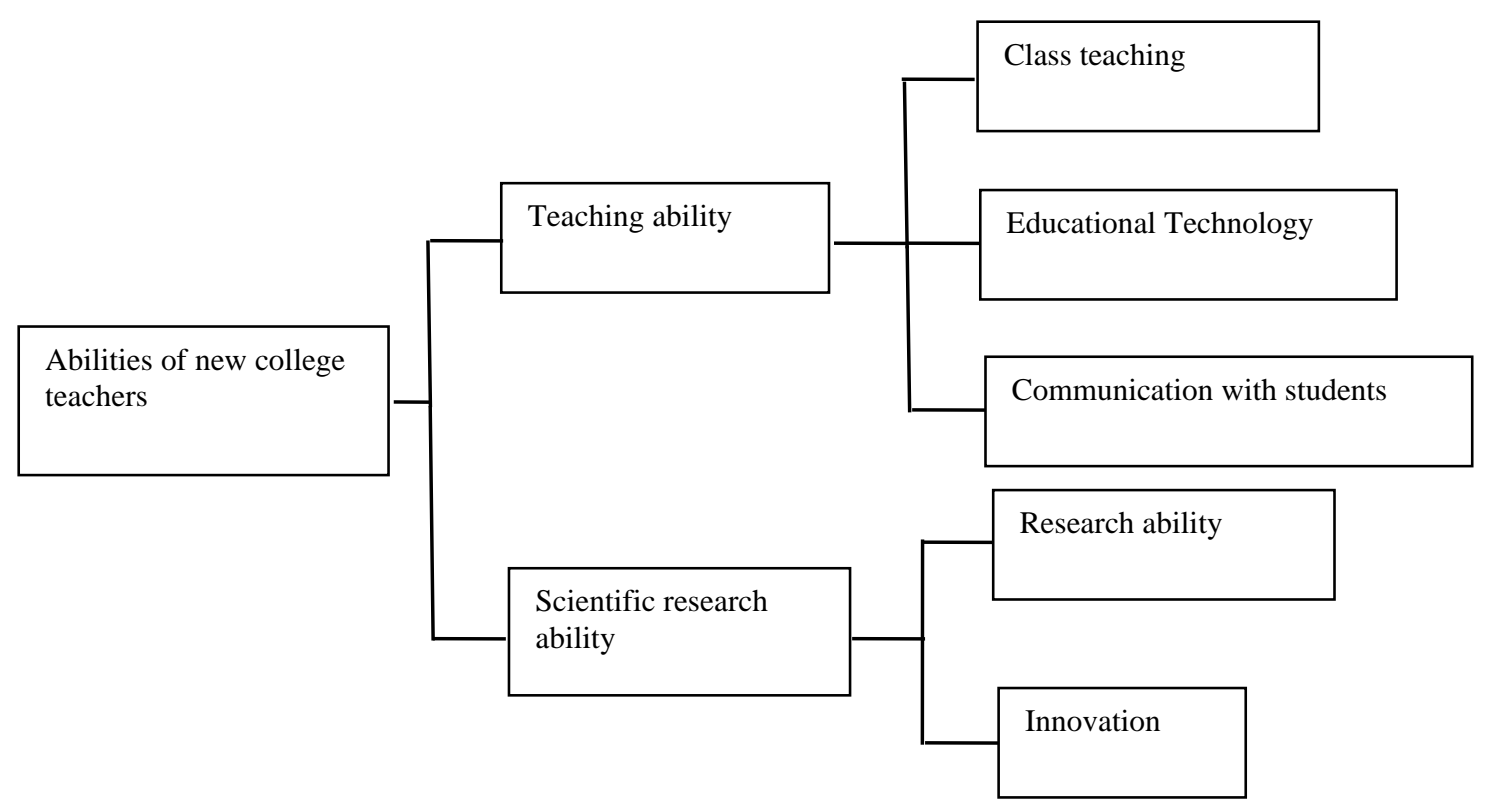

Figure 1. Abilities of new college teachers

So should implement more effective way to make young teachers really recognize their shortcomings and aspects for improvement, after the teachers will try to overcome their deficiencies, they advanced the practice to into teaching, and strive to maximum effectiveness, there are still certain difficulties.

\subsection{Tutor Training Measures}

The implementation of "Tutor Training" is to enhance the teaching ability of young teachers in universities, and promote the growth of young teachers, to provide a professional quality, strong operational capacity, high education level, young teachers with innovative spirit. We decided to implement the Young College Teachers teaching business capacity building program.

The teachers develop on four basic aspects: personal development, professional development, organizational development and teaching development. Personal development, including improving teachers' interpersonal skills, career planning and teachers health etc. Professional development refers to acquire or improve job-related knowledge and professional skills and concepts. Organizational development is focused on creating effective organizational climate. Teaching developments includes course preparation, teaching, curriculum updates and so on.

Selected a tutor for each newly recruited young teachers who has noble morality, superb professional skills, good teaching effect and has more than deputy senior professional. Tutor instructor training targets, research and teaching work, carry out during the training. The first year, the young teacher following the tutor in lectures, correcting homework, counseling students, and participate in research projects. The second year, the teacher teaches a course of the tutor conducting, tutor gives guidance on lesson plans, teaching perform.

Colleges should strengthen the daily management, supervise trainees to develop training programs, implementation of mentor, strengthen inspection and assessment.

\subsection{Benefits of the training method}

The tutor to train young teachers mainly on establishing modern education ideas, education concepts, mastery of advanced teaching methods and means to improve the young teachers teaching basic skills, training young teachers teaching organization, teaching evaluation, teaching research ability, teaching innovation, enhance the overall education level of young teachers.

Carefully selected experienced and excellent teachers as tutors for young teachers, they will guide them in ethics, teaching, scientific research and other aspects. To transfer young teachers how to be good teachers, college work, educational resource to improve their teaching capability, quality teaching and research capacity, and promote new teachers to better fulfill their duties. Mentor young teachers to participate in research projects, many young teachers graduated from other university, cannot be involved in research in the beginning. With tutors, led by the rapid growth of young 
teachers have a valid starting point platform. It is a new round of development of the college; it is an effective way to grow for young teachers as soon as possible.

Training will go hand in hand through the future work and life, tutor can guide on the young teacher living and personal development issues related to career and sustainable development even help them how to balance career and family by experience. Different people have different problems, more effective with one to one help. And young teachers should learn humbly to the tutors, getting the way of doing things, active learning, experience, as quickly as possible as their own style. Encourage young teachers to develop into a good political qualities, moral conduct, ambition, dedication on their own career.

\section{Summary}

Training of young teachers is an important task for universities to enhance the quality of teaching, the complexity of content cannot be underestimated. The issues of young college teachers in-depth are studied in this article. Both young teachers presented their own needs, but also with the development of the current demand for university, promotion the scientific research, education level of young teachers, to achieve the ability to enhance research and teaching quality of universities.

\section{Acknowledgements}

This study was supported by Hebei Province Education Department Research Project (2015 gjjg036).

\section{References}

[1]. Huijun Zhao: "Public Service on Campus": Reform and Development of Initial Training for College and University Faculty (D Hunan Normal University, China 2011).

[2]. Yi Li: A Research on Professional Development of Young teachers in local colleges and universities (D Yangtze University, China 2013).

[3]. Bin Zou.University Teachers' Professional Development and the Reform of the Distribution System.China Higher Education Research. (2013) No. 5, p. 63-67.

[4]. Jianxiong Huang: A Study on the Structural Optimization of Teaching Body in Local Universities and Colleges (D Central China Normal University, China 2012).

[5]. Li Jin: A Research on the Development of Teaching ability in a focal Undergraduate University (D Southwest University, China 2014).

[6]. Dandan Zheng: International Comparative Study on Teacher Educators and Professional Standards for Teacher Educators (D East China Normal University, China 2013).

[7]. Jingzhou Huang: The Study on In-service Education of Young College Teachers in China (D TianjinUniversity, China 2012).

[8]. Dongmei Wu, Yumin Wang. Review on the research of inductive teacher education for College Teachers. China Electric Power Education. (2013) No. 2, p. 149-150. 